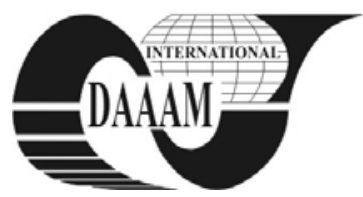

Annals of DAAAM for 2011 \& Proceedings of the 22nd International DAAAM Symposium, Volume 22, No. 1, ISSN 1726-9679 ISBN 978-3-901509-83-4, Editor B. Katalinic, Published by DAAAM International, Vienna, Austria, EU, 2011 Make Harmony between Technology and Nature, and Your Mind will Fly Free as a Bird Annals \& Proceedings of DAAAM International 2011

\title{
QUALITY OF MACHINED SURFACE DURING CO2 LASER CUTTING OF ALLOY STEELS
}

\author{
CEKIC, A[hmet]; KULENOVIC, M[alik] \& BEGIC, D[erzija]
}

\begin{abstract}
It is necessary to understand the effect of all relevant parameters on the process productivity and cut quality for optimal design of processing technologies regarding different types and thickness of materials. In this paper, the experimental results of the influence the process parameters on the characteristics of cut quality in $\mathrm{CO}_{2}$ laser cutting of alloy steels 1.457 and 1.4828 are presented. Nitrogen and oxygen are used as assist gases. There were significant improvements in material savings by reducing the kerf width and heat affected zone, and in increasing of quality of machined surface.

Key words: $\mathrm{CO}_{2}$ laser cutting, kerf width, heat affected zone, surface roughness
\end{abstract}

\section{INTRODUCTION}

Due to widespread application of laser cutting technology in metal processing industry, problem that is imposing is choosing the optimal process parameters. Specifically, product quality, material savings and productivity during the cutting of machined materials with lasers are primarily dependent on the process parameters that are mutually non-linearly related (Rajaram, et al., 2003). The most influential parameters are: laser power, focus position, cutting speed, distance nozzle, type and pressure of assist gas (Al-Sulaiman et al., 2006).

The paper presents results of experiments obtained by cutting two different alloy steels. Namely, due to increased application of temperature resistance special alloyed steel in automobile industry, the need for research aimed at optimization of cutting parameters in laser cutting of these steels. Experiments were performed on the $\mathrm{CO}_{2}$ laser because it is most common in industrial metal cutting technology due to their greater output power and quality of the laser beam, thus able to achieve higher cutting speed. Based on our complete analysis of the results, the optimal cutting parameters that enable to achieve the required surface finish, minimum kerf width and heat affected zone (the maximum material saving) in achieving the maximum possible cutting speed (maximum productivity) are defined.

Criteria for evaluating the quality of the cut during the laser cutting are: surface roughness (DIN 4768), machined surface quality (DIN 2310), the kerf width, heat input, dimensional control, change of structure and microhardness of the machined material, etc. With detailed analysis of the influence of process parameters on these indications of quality of cut, it is possible to determine the optimum value of these parameters (Cekic et al., 2008).

However, so far the performed researches the effect of the process parameters on the quality of cut during laser cutting of these alloy steels do not contain an integrated approach (Avanish and Vinod, 2008). In experiments with one to three variable parameters, it is not possible to determine the interaction between all the influential parameters, which is not possible to determine the multi influence of several parameters on the quality of cut, productivity as well as justification of the application of this technology (Lamikiz, et al., 2005).

\section{EXPERIMENTAL PROCEDURE}

Experiments were conducted at the department of Technical Sciences (Fachbereich Sci Tec) on the University of Jena, Germany. Bearing in mind that a large number of process parameters effect on the laser cutting process, such as when performing experiments placed the following limitations:

- Experiments were conducted in two different steels. The main aim of this research was the optimization of process parameters in laser cutting of temperature resistance special alloyed steel 1.4828 (X15CrNiMoSi20-12, $3 \mathrm{~mm}$ thick). Order to compare results, were also performed research on steel 1.4571 (X6CrNiMoTi17-12-2, 4 mm thick).

- Cutting is performed with different combinations of process parameters on the $\mathrm{CO}_{2}$ laser - Rofin DC020. The sample geometry and schematic illustration of various cut quality attributes are shown in Fig. 1.

- During the experiment the following parameters are held constant: the laser power - $2000 \mathrm{~W}$, wavelength of the laser beam - 10600nm, mode of operation - $\mathrm{cw}$, focal length of lens $-127 \mathrm{~mm}$, focused spot size $-0,21 \mathrm{~mm}$ and nozzle diameter $-2 \mathrm{~mm}$.

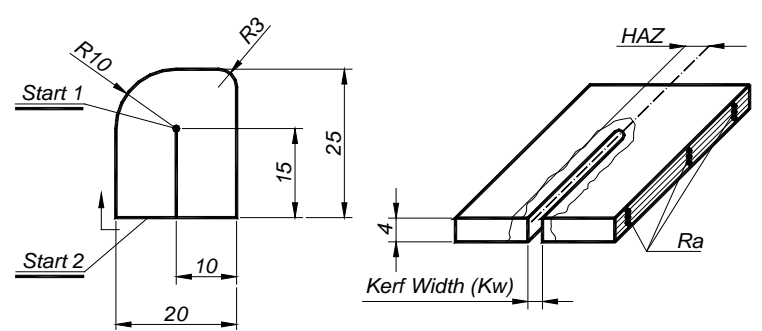

Fig. 1. The Sample Geometry and Schematic illustration of various cut quality attributes.

Quality of the laser cutting on above mentioned steel is analyzed by measuring the following three parameters: the kerf width (Kw), the heat affected zone (HAZ) and surface roughness $(\mathrm{Ra})$. Previous experimental results showed that the most influential parameters on these three indications of quality of the cut are: cutting speed (V), assist gas pressure (p) and the focus position (FP). The values of the parameters that were varied during the experiments are presented in Table 1.

\begin{tabular}{|c|c|c|c|}
\hline \multicolumn{4}{|c|}{$\mathrm{CO}_{2}$ laser cutting using $\mathrm{O}_{2}$ as assist gas } \\
\hline Varied parameters: & \multicolumn{3}{|c|}{ Values: } \\
\hline Cutting speed, V [mm/min] & 2000 & 3000 & 4000 \\
\hline Focus position, FP [mm] & $-1,0$ & 0.0 & 1,0 \\
\hline Gas pressure $-\mathrm{O}_{2}, \mathrm{p}$ [bara] & 12,5 & 15,0 & 17,5 \\
\hline \multicolumn{4}{|c|}{$\mathrm{CO}_{2}$ laser cutting using $\mathrm{N}_{2}$ as assist gas } \\
\hline Varied parameters: & & Value & \\
\hline Cutting speed, V [mm/min] & 500 & 750 & 1000 \\
\hline Focus position, FP [mm] & $-1,0$ & 0.0 & 1,0 \\
\hline Gas pressure $-\mathrm{N}_{2}, \mathrm{p}$ [bara] & 10,0 & 12,5 & 15,0 \\
\hline
\end{tabular}

Tab. 1. Plan of the experiment 


\section{RESULTS AND DISCUSSION}

Because of the clarity of results, in Figures 2 and 3 are presented the results only for the minimum value of kerf width and HAZ during cutting of estimated steels for these the varied cutting parameters by using $\mathrm{O}_{2}$ and $\mathrm{N}_{2}$, respectively.

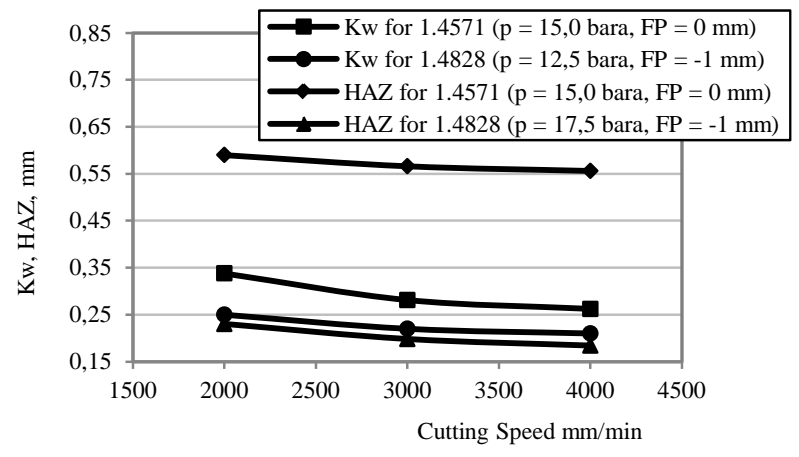

Fig. 2. The change of kerf width and HAZ in laser cutting of steel $1.4571(\mathrm{~s}=4 \mathrm{~mm})$ and $1.4828(\mathrm{~s}=3 \mathrm{~mm})$ using $\mathrm{O}_{2}$ as assist gas

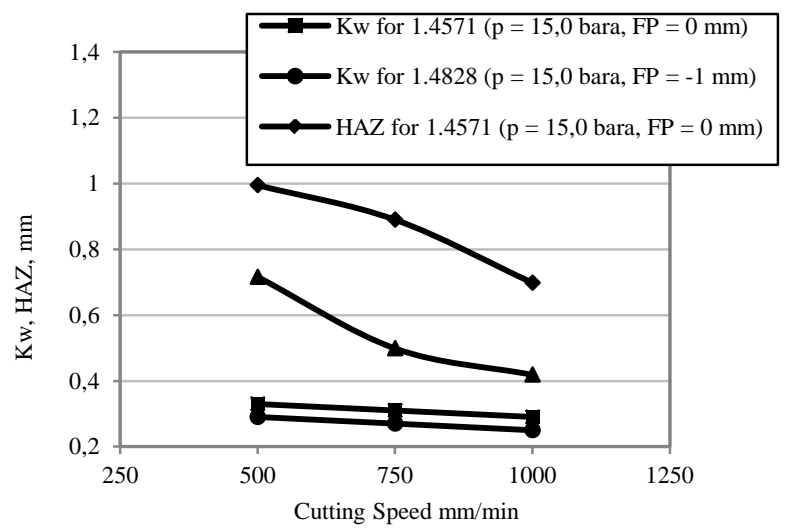

Fig. 3. The change the kerf width $(\mathrm{Kw})$ and HAZ in laser cutting of steel $1.4571(\mathrm{~s}=4 \mathrm{~mm})$ and $1.4828(\mathrm{~s}=3 \mathrm{~mm})$ using $\mathrm{N}_{2}$ as assist gas

Figure 4 shows the minimum value of the parameter $\mathrm{Ra}$ during the process of cutting steel for defined range of the varied parameters using $\mathrm{O}_{2}$ and $\mathrm{N}_{2}$ as assist gases.

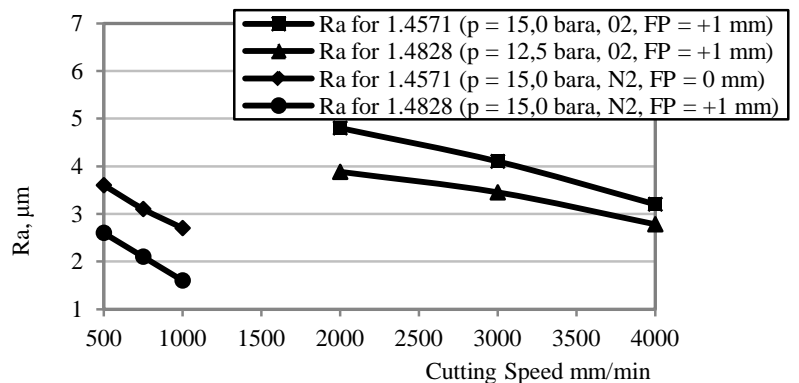

Fig. 4 . The change Ra value for laser cutting steel 1.4571 ( $\mathrm{s}=4$ $\mathrm{mm})$ and $1.4828(\mathrm{~s}=3 \mathrm{~mm})$ using $\mathrm{O}_{2}$ and $\mathrm{N}_{2}$ as assist gases

For given experimental conditions, the difference in the kerf width is $0.145 \mathrm{~mm}$, while for the HAZ is $0.582 \mathrm{~mm}$ during the cutting of steel 1.4571 (material saving). It may be noted that cutting of steel 1.4828 is giving smaller kerf width and HAZ compared to other steel due to less thickness. This confirms that the thickness of the material is one of the important factors that should be taken into account in the analysis of other process parameters. The value of HAZ is smaller when the focus position is above the workpiece surface, but due to higher cutting speed the focus position on the workpiece surface is far more favorable. Also, it is important to note that in varied range of cutting parameters for a particular position of the focus, value of the parameter Ra is located at an interval that belongs to the same class of roughness.

\section{CONCLUSION}

Many researchs have been conducted regarding influence of process parameters on the quality of cut during $\mathrm{CO}_{2}$ laser cutting of two different alloyed steels by using $\mathrm{O}_{2}$ and $\mathrm{N}_{2}$ as assist gas. For these experimental conditions the most important research findings are as follows:

- With laser cutting by using $\mathrm{O}_{2}$ as assist gas, the minimum kerf width and HAZ (the maximum savings of material) were obtained with the following conditions: $\mathrm{p}=15,0$ bar, $\mathrm{V}=4000 \mathrm{~mm} / \mathrm{min}, \mathrm{FP}=0 \mathrm{~mm}$ (1.4571), $\mathrm{p}=12,5 \mathrm{bar}, \mathrm{V}=4000 \mathrm{~mm} / \mathrm{min}, \mathrm{FP}=-1 \mathrm{~mm}$ (1.4828).

- With laser cutting by using $\mathrm{N}_{2}$ as assist gas the minimum kerf width and HAZ (the maximum savings of material) were obtained with the following conditions:

$\mathrm{p}=15,0 \mathrm{bar}, \mathrm{V}=1000 \mathrm{~mm} / \mathrm{min}, \mathrm{FP}=0 \mathrm{~mm}$ (1.4571), $\mathrm{p}=15,0$ bar, $\mathrm{V}=100 \mathrm{~mm} / \mathrm{min}, \mathrm{FP}=-1 \mathrm{~mm}(1.4828)$.

- Surface roughness increases from the input laser beam into the workpiece to the exit. To obtain a small value of the parameter Ra should strive as much as cutting speed with a focus position above the workpiece.

- During laser cutting of steel by using N2, it is obtained brighter and smoother surfaces and better cutting edge than in the use of active gases (O2), but the cutting speed is smaller. Although, due to adhesion and high viscosity of melted material on the underside of the workpiece appear dross. The recommendation is to use a higher pressure than 10 bars to eliminate this problem.

Further researches will be based on cutting different thickness materials and curved surfaces (tubes) from related groups of alloy steels. As experimental results show that one can define a common model for a certain interval of variation of variable parameters which will be valid for a certain material thickness and approximately similar chemical composition, authors plan to work on mathematical modeling of cutting process of alloy steels.

\section{ACKNOWLEDGEMENTS}

The authors gratefully acknowledge the support of the Department of Laser and Opto-Technologies at the University of Applied Science Jena, Germany for this work.

\section{REFERENCES}

Al-Sulaiman, F.A.; Yilbas, B.S. \& Ahsan M. (2006). CO2 laser cutting of a carbon/carbon multi-lamelled plain-weave structure. Journal of Material Processing Technology, 173, (April 2006) page numbers (345-351), ISSN: 0924-0136

Avanish, K. D. \& Vinod, Y. (2008). Laser beam machining-A Review. International Journal of Machine Tools and Manufacture, 48, (May 2008) page numbers (608-628), ISSN: 0890-6955

Cekic, A.; Kulenović, M. \& Begic Dj. (2008). Roughness as parameter of cut quality during $\mathrm{CO}_{2}$ laser cutting of high alloy steels for the special purpose. Proceedings of the 19th International DAAAM Symposium, Katalinic, B., pp. 225226, ISBN 978-3-901509-68-1, Wienna, 2008, Published by DAAAM International, Austria

Lamikiz, A.; Lopez de Lacalle, L. N.; Sanchez, J. A.; Pozo, D.; Etayo.J. M. \& Lopez. J. M. (2005). CO2 laser cutting of advanced high strength steels (AHSS). Applied Surface Science, 242 (April 2005) page numbers (362-368), ISSN: 0169-4332

Rajaram, N.; Sheikh-Ahmad, J. \& Cheraghi, S. H. (2003). CO2 laser cut quality of 4130 steel. International Journal of Machine Tools and Manufacture, 43, (March 2003) page numbers (351-358), ISSN: 0890-6955 